\title{
DETERMINATION OF ULTIMATE SHEAR STRENGTH OF REINFORCED CONCRETE BEAMS WITHOUT WEB REINFORCEMENT BY A COMBINED UPPER AND LOWER BOUND ANALYSIS
}

\author{
By TAN Kiang Hwee*, Akio HASEGAWA** and Fumio NISHINO***
}

\begin{abstract}
The combined upper and lower bound analysis is used to predict the shear strength of reinforced concrete beams without web reinforcement. Theoretical considerations reveal that the ultimate shear strength of a beam with given material and sectional properties may be expressed as a single continuous function of its shear span to effective depth ratio. Numerical computations for the ultimate shear strength of beams with steel reinforcement tatios of $0.028,0.0188$ and 0.008 and shear span to effective depth ratios of 1 to 8 are carried out. In addition, the contribution pf compression zone, aggregate interlock and dowel action to the shear capacity of the beam are determined and the failure modes of the beams are examined. The results are compared with available experimental data and the possibility of the use of the combined upper and lower bound analysis for other structural members is indicated.
\end{abstract}

\section{INTRODUCTION}

The shear strength of reinforced concrete beams has been extensively studied by many researchers ${ }^{1)}$. Most of these studies, however, were carried out experimentally and existing design formulae for shear failure are mostly semi-empirical in nature. Morever, such design formulae are based on test results of beams within a certain range of variables and may not be generally applicable to beams with different design variables. Theoretical works on the subject are therefore desirable as experimental studies to cover a wide range of design variables would be too costly.

However, a review of literature shows that theoretical studies were few and these are based on two main approaches : 1) the so-called 'arch' or 'truss' analogies and 2) plastic theories. The former is an established method of approach but its application is limited to beams. On the other hand, the latter, a relatively new approach, is considered to be more attractive in that it can be easily extended for applications to other concrete members such as columns and slabs. Nevertheless, both approaches have not been able to provide a complete understanding of the failure mechanism of reinforced concrete beams subjected to shear.

This study, therefore, attempts to evaluate the ultimate shear strength of reinforced concrete beams without web reinforcement from a purely theoretical point of view. For this purpose, the combined upper and lower bound analysis ${ }^{2}$ is used. The validity of the method is investigated by carrying out numerical computations for a series of beams with tension reinforcement ratios of $0.028,0.0188$ and 0.008 and shear

* Member of JSCE, Dr. Eng., Lecturer, Dept. of Civil Eng., National University of Singapore (Kent Ridge, Singapore).

** Member of JSCE, Dr. Eng., Asso. Prof., Dept. of Civil Eng., Univ. of Tokyo (Bankyo-ku, Tokyo).

*** Member of JSCE, Ph. D., Prof., Vice-President for Academic Affairs, Asian Institute of Technology (Bangkok, Thailand) on leave from University of Tokyo. 
span to effective depth ratios varying from 1 to 8 . Next, to understand the failure mechanism of beams subject to shear, this paper examines the collapse modes and the relative contribution of compression zone, aggregate interlock and dowel action to the total shear strength of the beam based on the numerical studies. From analytical considerations, a general form of the expression for the ultimate shear strength as a continuous function of tension reinforcement ratio and shear span to effective depth ratio is also suggested.

\section{ANALYTICAL CONSIDERATIONS}

The shear strength of reinforced concrete beams is hereby investigated by a combined upper and lower bound analysis ${ }^{2)}$. This method of limit analysis combines the features of the upper bound theorem and lower bound theorem and has the advantage that the various possible collapse modes of failure can be collectively represented in a general from. Furthermore, it allows the relative contribution of the various elements to the ultimate strength to be determined at the same time. In this method, an explicit expression for the desired strength is first derived from equilibrium conditions. The ultimate strength is then obtained by maximizing the expression with respect to static variables and minimizing with respect to kinematic variables subjected to constraints which result from assumed collapse mechanism and yield conditions.

a) Model and assumptions

The shear failure of reinforced concrete beam is normally investigated by testing a simply supported beam under a symmetrical two-point load as shown in Fig. 1. The present study considers a beam with a prismatic, rectangular cross-section and with bottom longitudinal reinforcement only. The analysis is based on the following assumptions:

a) Plane stress condition is considered.

b) The beam fails by the formation of a shear crack as shown in Fig. 2. Referring to the cartesian coordinate system shown in the figure, the shape of the crack is assumed to be given by an equation $x=g(y)$. Collapse is considered to be either due to the failure of concrete above the crack at the critical section or yielding of the tension reinforcement at the lower end of the crack.

c ) The force per unit area due to aggregate interlock action is assumed to be constant over the crack surface.

d) Anchorage of reinforcement is adequate and bond slip does not occur.

e) Concrete and steel are assumed to be elastic-perfectly plastic materials.

b) Equilibrium equations

Considering the free body in Fig. 2, the equilibrium equations may be written as:

$V-V_{c}-F_{d}-b \int_{s} f \sin \theta d s=0$

$F_{s}-C-b \int_{s} f \cos \theta d s=0$

$V_{c} a-b \int_{s} f \cos \theta y d s+b \int_{s} f \sin \theta x d s-C \bar{y} h$

$+F_{d}\left(\gamma a+x_{0}\right)+F_{s}(h-d)=0$

where $C=$ normal force acting on concrete compression zone,
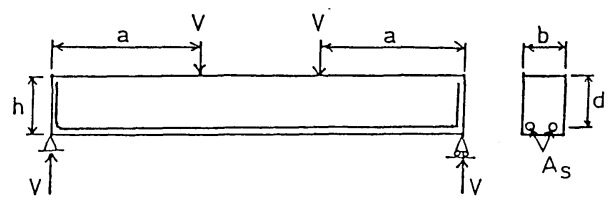

Fig. 1 Reinforced Concrete Beam Under Two-point Load.

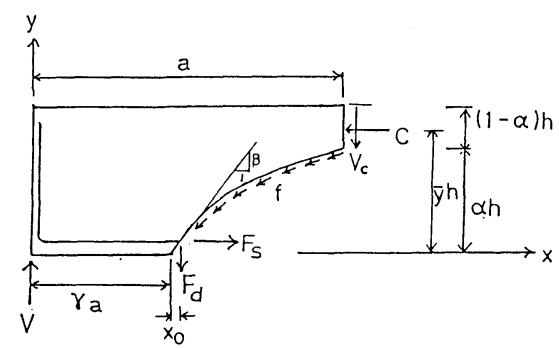

Fig. 2 Collapse Mechanism for Analysis. 
$f=$ force per unit area due to aggregate interlock action,

$F_{d}=$ shear force acting on longitudinal reinforcement due to dowel action,

$F_{s}=$ axial force acting on longitudinal steel reinforcement,

$V=$ total shear force on beam at critical section,

$V_{c}=$ shear force acting on concrete compression zone,

$a=$ shear span,

$b=$ width of beam,

$d=$ effective depth of beam,

$h=$ total depth of beam,

$x_{0}=$ distance between line of action of shear force $F_{d}$ and the lower end of shear crack, measured along $x$-axis,

$\bar{y}=$ distance between line of action of compressive force $C$ and $x$-axis divided by total depth of beam,

$\theta=$ angle of inclination of shear crack to $x$-axis at any point $(x, y)$,

$\alpha=$ distance between upper end of shear crack and $x$-axis divided by total depth of beam,

$\beta=$ slope of shear crack at its lower end,

$\gamma=$ distance between lower end of shear crack and support divided by shear span of beam, and the integration is carried out over the entire length of the shear crack. The shape of the crack is assumed be in the form of

$$
x=g(y) \equiv p+q y+r y^{2}
$$

where $p, q$ and $r$ are constants. Applying the end conditions (that is, when $x=\gamma a, y=0, d y / d x=\beta$ and when $x=a, y=\alpha h)$, the parameters $p, q$ and $r$ can be expressed in terms of $\alpha, \beta$ and $\gamma$ as

$$
p=\gamma a, \quad q=\frac{1}{\beta}, \quad r=\frac{a(1-\gamma)}{(\alpha h)^{2}}-\frac{1}{\alpha \beta h} \text {. }
$$

Using Eqs. (2) and (3) and introducing non-dimensional terms as

$$
\begin{aligned}
& \lambda \equiv \frac{a}{d}, \quad \mu \equiv \frac{d}{h}, \quad \rho \equiv \frac{A_{s}}{b d}, \quad \xi \equiv \frac{f_{y}}{f_{c}^{\prime}} \\
& v \equiv \frac{V}{b h f_{c}^{\prime}}, \quad \sigma_{c} \equiv \frac{C}{b h(1-\alpha) f_{c}^{\prime}}, \quad \tau_{c} \equiv \frac{V_{c}}{b h(1-\alpha) f_{c}^{\prime}}, \\
& \sigma_{s} \equiv \frac{F_{s}}{A_{s} f_{y}}, \quad \tau_{s} \equiv \frac{F_{d}}{A_{s} f_{y}}, \quad \bar{f} \equiv \frac{f}{f_{c}^{\prime}}
\end{aligned}
$$

in which $f_{c}^{\prime}$ is the compressive strength of concrete and $A_{s}$ and $f_{y}$ are the area and yield strength of tension reinforcement, the equilibrium equations (1) may be re-stated as:

$$
\begin{aligned}
& v=(1-\alpha) \tau_{c}+\rho \mu \xi \tau_{s}+\alpha \bar{f} \\
& (1-\alpha) \sigma_{c}-\rho \mu \xi \sigma_{s}+(1-\gamma) \mu \lambda \bar{f}=0 \\
& \frac{(1-\alpha) \bar{y}}{\lambda \mu} \sigma_{c}-(1-\alpha) \tau_{c}-\rho \xi(1-\mu) \frac{\sigma_{s}}{\lambda} \\
& -\rho \mu \xi\left[\gamma+\frac{1}{\alpha \beta \lambda \mu}(1-\mu)(\alpha-1+\mu)+\frac{(1-\gamma)}{\alpha^{2}}(1-\mu)^{2}\right] \tau_{s}-\frac{\alpha}{3}\left\{(4 \gamma-1)+\frac{\alpha}{\beta \lambda \mu}\right\} \bar{f}=0
\end{aligned}
$$

The equilibrium equations thus constitute one equation for the value of $v$ [Eq. (6)] and two equality constraints [at $(7)$ and $(8)]$. It is noted that these equations are obtained by considering a static stress field defined by variables $\sigma_{c}, \tau_{c}, \sigma_{s}, \tau_{s}, \bar{f}$, which is compatible with a kinematic velocity field defined by variables $\alpha, \beta$ and $\gamma$. The value of $v$ is dependent only on these variables for given quantities of $\xi, \mu, \rho$ and $\lambda$. For the assumed fields to be admissible, the static and kinematic variables must satisfy additional constraints given as follows. It is further noted that the values of $\sigma_{c}$ and $\bar{y}$ in Eqs. (7) and ( 8 ) are dependent on the normal stress distribution across the compression zone. 
c) Stress-strain relations

The concrete and steel reinforcement are considered to be elastic-perfectly plastic materials as shown in Fig. 3. Hence, the stress-strain relations may be written as:

$$
\sigma_{c}=\left\{\begin{array}{cc}
\varepsilon_{c} / \varepsilon_{c 0} & \left(\varepsilon_{c} \leq \varepsilon_{c 0}\right) \\
1 & \left(\varepsilon_{c}>\varepsilon_{c 0}\right)
\end{array} .\right.
$$

for concrete and

$$
\sigma_{s}=\left\{\begin{array}{cc}
\varepsilon_{s} / \varepsilon_{s 0} & \left(\varepsilon_{s} \leq \varepsilon_{s 0}\right) \\
1 & \left(\varepsilon_{s}>\varepsilon_{s 0}\right)
\end{array} .\right.
$$

for steel longitudinal reinforcement, where $\varepsilon_{c 0}=f_{c}^{\prime} / E_{c}, \varepsilon_{s 0}=f_{y} / E_{s}$, and $E_{c}$ and $E_{s}$ are the modulii of elasticity of concrete and steel respectively.

d) Normal strain and stress distributions across compression zone

Assume that at failure, the two rigid parts of the beam rotates about the lower edge of the concrete compression zone as shown in Fig. 4. The normal strain distribution can then be assumed to be linear along the boundary 1-2 between the two rigid parts. Correspondingly, the concrete compression zone can be either in a 'fully elastic' (Case I) or an 'elastic-plastic' (Case II) state as shown in Fig. 5.

Considering the normal stress distribution across the concrete compression zone, the values of $\sigma_{c}$, defined as the non-dimensional average normal stress in the concrete compression zone in Eq. ( 5$)$, and $\bar{y}$ in Eq. ( 8 ) can be expressed as:

Case I $\left(0 \leq \sigma_{c} \leq 1 / 2\right.$ or $\left.0 \leq \eta_{1} \leq 1\right)$ :

$$
\begin{aligned}
& \sigma_{c}=\eta_{1} / 2 \\
& \bar{y}=(\alpha+2) / 3
\end{aligned}
$$

Case II $\left(1 / 2 \leq \sigma_{c} \leq 1\right.$ or $\left.0 \leq \eta_{2} \leq 1\right)$ :

$$
\begin{aligned}
& \sigma_{c}=\left(1-\eta_{2} / 2\right) \\
& \bar{y}=\alpha+(1-\alpha)\left(3-{\eta_{2}}^{2}\right) /\left(6-3 \eta_{2}\right)
\end{aligned}
$$

e ) Strain compatibility

The strain compatibility is thought to become progressively less significant as ultimate (i. e. plastic) conditions are approached. Hence, for simplicity, the normal strain distribution along the boundary 1-2-3 as shown in Fig. 5 may be assumed. Denoting the strains in the steel longitudinal reinforcement by $\varepsilon_{s}$, the condition of strain compatibility may then be expressed as follows:

$$
\varepsilon_{s}=\frac{d_{s}}{(1-\alpha) h} \varepsilon_{c r}
$$
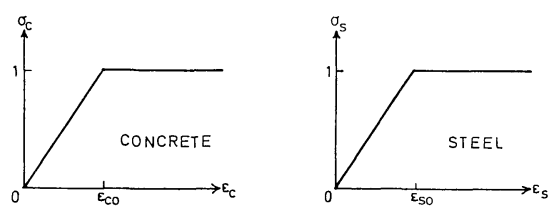

Fig. 3 Stress-strain Relations for Concrete and Steel.

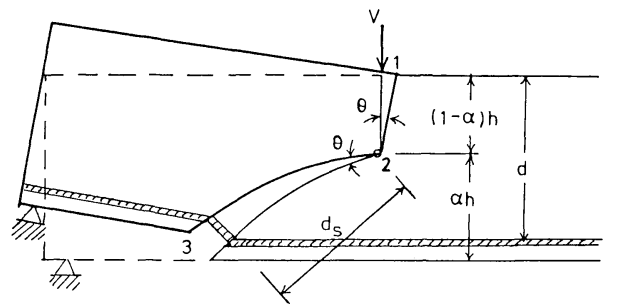

Fig. 4 Assumed Displacement Field Prior to Collapse.
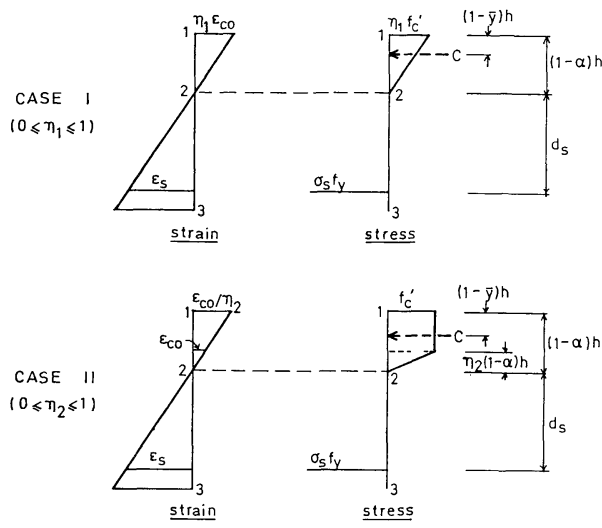

Fig. 5 Strain Compatibility. 
where $d_{s}$ is the distance from the centre of rotation 2 to the point where the crack cuts the tension reinforcement and $\varepsilon_{c r}$ is the normal strain in the extreme fibre of the concrete compression zone defined respectively as:

$$
\begin{aligned}
& d_{s}=h \sqrt{(\alpha-(1-\mu))^{2}+\left((1-\gamma) \lambda \mu-x_{0} / h\right)^{2}} \\
& \varepsilon_{c r}= \begin{cases}\varepsilon_{c 0} \eta_{1} & \text { [Case I }] \\
\varepsilon_{c 0} / \eta_{2} & \text { [Case II }]\end{cases}
\end{aligned}
$$

Introducing the stress-strain relations at (9) and the definitions of $\eta_{1}$ and $\eta_{2}$ at (13) into (11) result in the following constraint on the static variables $\sigma_{c}$ and $\sigma_{s}$ :

Case I $\left(0 \leq \sigma_{c} \leq 1 / 2\right)$ :

$$
\sigma_{s}=\min \left\{\frac{d_{s} / h}{(1-\alpha)} \cdot \frac{2 \sigma_{c} E_{s}}{E_{c} \xi}, 1\right\}
$$

Case II $\left(1 / 2 \leq \sigma_{c} \leq 1\right)$ :

$$
\sigma_{s}=\min \left\{\frac{d_{s} / h}{(1-\alpha)} \cdot \frac{E_{s}}{2\left(1-\sigma_{c}\right) E_{c} \xi}, 1\right\}
$$

\section{f) Yield conditions}

The steel reinforcement as well as the compression zone are each subject to normal and shear forces. Consequently, an interactive yield condition is required for each material. For steel, von Mises yield criterion is assumed and this results in the following constraint:

$$
3 \tau_{s}^{2}+\sigma_{s}^{2} \leq 1
$$

For concrete, the failure criterion proposed by Bresler and Pister ${ }^{3)}$ is used so that

$$
\tau_{c} \leq 0.1\left[0.62+10.10 \sigma_{c}+5.80 \sigma_{c}{ }^{2}-18.60 \sigma_{c}{ }^{3}+2.09 \sigma_{c}{ }^{4}\right]^{1 / 2}
$$

It is further assumed that $\sigma_{c}, \tau_{c}, \sigma_{s}, \tau_{s}$ and $\bar{f}$ are all positive, that is,

$\sigma_{c} \geq 0, \tau_{c} \geq 0, \sigma_{s} \geq 0, \tau_{s} \geq 0, \bar{f} \geq 0$

No upper bound is imposed on the value of $\bar{f}$, which is, however, subjected to the equality constraints at (7) and (8).

g) Collapse mechanism

The collapse mechanism is defined by the position and shape of the shear crack. The kinematic variables $\alpha, \beta$ and $\gamma$ are as defined in Fig. 2. They are used to describe the collapse mechanism and are subjected to the following constraints :

$$
\begin{aligned}
& 1-k \mu \leq \alpha \leq 1 \cdots \\
& \frac{\alpha h}{a(1-\gamma)} \leq \beta<\infty \\
& 0 \leq \gamma \leq 1 \cdots \cdots \cdots
\end{aligned}
$$

where $k=\sqrt{\rho^{2} n^{2}+2 n \rho}-n \rho$ and $n=E_{s} / E_{c}$. The lower bound imposed on the value of $\alpha$ at (18) comes from the assumption that the top end of the shear crack must be above the neutral axis of the beam, the position of which is calculated from service condition of the beam under flexure $e^{4)}$. The lower bound imposed on the value of $\beta$ is due to the assumption that the shear crack generally curves upwards and assumes a straight line at the limit.

The collapse of beam is assumed to be due to the failure of concrete compression zone or the yielding of the longitudinal steel reinforcement. For this to be valid, either

$$
3 \tau_{s}^{2}+\sigma_{s}^{2}=1
$$

or

$$
\tau_{c}=0.1\left[0.62+10.10 \sigma_{c}+5.80 \sigma_{c}{ }^{2}-18.60 \sigma_{c}{ }^{3}+2.09 \sigma_{c}{ }^{4}\right]^{1 / 2}
$$

must be satisfied. 


\section{SOLUTION PROCEDURE}

It has noted from Eqs. (6) to ( 8 ) that for given values of $\xi, \mu, \rho$ and $\lambda$, the value of $v$ is a function of eight variables, namely three kinematic variables $\{\alpha, \beta, \gamma\}$ and five static variables $\left\{\sigma_{c}, \tau_{c}, \sigma_{s}, \tau_{s}, \bar{f}\right\}$. The combined upper and lower analysis gives the ultimate shear strength $v_{u}$ as the value of $v$ which is minimized with respect to the kinematic variables and maximized with respect to the static variables, that is,

$$
v_{u}=\min _{k}\left\{\begin{array}{cc}
\max & v(k, s)
\end{array}\right\}
$$

subject to

$$
\left.\begin{array}{ll}
G_{i}(k, s)=0 & (i=1,2, \cdots) \\
H_{j}(k, s) \geq 0 & (j=1,2, \cdots)
\end{array}\right\}
$$

where $k=\{\alpha, \beta, \gamma\}$ and $s=\left\{\sigma_{c}, \tau_{c}, \sigma_{s}, \tau_{s}, \bar{f}\right\}$ The value of $v$ is given by Eq. (6) while the constraints $G_{i}(k, s)$ and $H_{j}(k, s)$ are given at $(7),(8),(14),(21)$ and (15) - (20) respectively. It can be seen from Eqs. (22) and (23) that the problem is equivalent to a constrainted optimization problem.

To calculate the value of $v_{u}$ numerically, the value of $v$ [Eq. (6)] is first maximised with respect to $s$ for all possible values of $k$. This gives the function $v(k)=\left.\max _{S} v(\bar{k}, s)\right|_{\text {anl }} \bar{k}$, which is then minimized with respect to $k$ to give the desired ultimate strength $v_{u}$. It should be noted that by such a solution procedure, the accuracy of the calculated value of ultimate strength will depend on the number of assumed values of $k$ and $s$.

\section{EQRATIONS FOR ULTIMATE SHEAR STRENGTH AND RELATIVE BEAM STRENGTH}

Experimental results by Kani ${ }^{5)}$ show that for a given cross-section and material properties, the ultimate load-carrying capacity of beams without web reinforcement and their corresponding modes of failure are dependent on the shear span to effective depth ratio, $\lambda$. This is as shown in Fig. 6 , where $m$ is the relative beam strength defined as the ultimate moment $M_{u}$ divided by flexural moment capacity $M_{f l}$ of the beam. It can be seen that the flexural capacity of the beams is not attained for $\lambda$ between $\lambda_{1}$ (approximately equal to 1.5) and $\lambda_{u}$ (approximately 7). The beam fails by 'arch action' (shear-compression or shear-tension failures) and 'beam action' (diagonal tension failure) in the shear span respectively for values of $\lambda$ less and greater than $\lambda_{i}$ (which is about 2.5).

The equation for the shear strength of beams failing by 'beam action' is well established. In his rational theory, Kani ${ }^{6}$ ) proposed an equation in which $m$ is proportional to $\lambda$. Recently, Okamura et al ${ }^{7}$. proposed a design equation in which $m$ increases linearly with $\lambda$ whereas Zsutty8), through a combination of dimensional analysis and statistical regression analysis, derived a prediction equation in which $m$ is

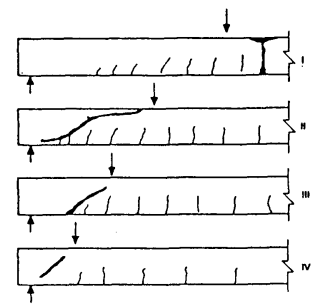

(a) Collapse Modes

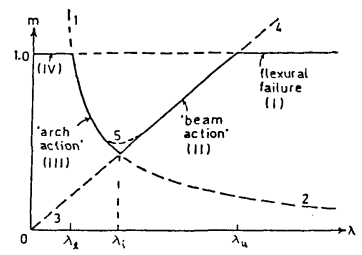

(b) Relation between $m$ and $\lambda$

Fig. 6 Collapse Modes and Relative Beam Strength of Beam subjected to Two-point Loading (Experimental Observations). 
proportional to $\lambda^{2 / 3}$. According to the ACI code ${ }^{9)}$, the value of $m$ also increases linearly with $\lambda$.

On the other hand, the equation for the strength of beams failing by 'arch action' has not been established yet. Zsutty ${ }^{10)}$ obtained $m$ as proportional to $\lambda^{-1 / 3}$ whereas Kani ${ }^{6)}$ and Kotosov ${ }^{11)}$ proposed that the relative beam strength $m$ is inversely proportional to the shear span to effective depth ratio $\lambda$. Others like Nielsen et $\mathrm{al}^{12)}$. and Kemp et $\mathrm{al}^{13)}$. derived expressions which do not give $m$ as a simple function of $\lambda$. The ACI code ${ }^{9)}$ gives $m$ as the sum of terms containing $\lambda^{2}, \lambda$, and a constant for such beams.

Nevertheless, the consideration of two different collapse modes, that is, failure by 'arch action' and failure by 'beam action' may not be consistent with the upper bound theorem of limit analysis. According to the upper bound theorem, the beam should fail when the lowest of the strengths predicted for all possible collapse modes is reached. Hence, contrary to experimental results, the beam should have failed by 'beam action' for $\lambda$ less than $\lambda_{i}$ and by 'arch action' for $\lambda$ greater than $\lambda_{i}$. To avoid this anomaly, the relative beam strength should better be expressed as a single continuous function of the shear span to depth ratio for beams failing under shear. In other words, the two curves 1-2 and 3-4 in Fig. 6(b), which represent failure by 'arch action' and 'beam action' respectively, should be replaced by a single continuous curve 1-54 in order to achieve consistency with the upper bound theorem of limit analysis.

In the present analysis, by eliminating the variables $\tau_{c}$ and $\bar{f}$ from Eq. (6) with the use of Eqs. (( 7$)$ and (8), the value of $v$ can be expressed as:

$$
\begin{aligned}
& v=\frac{\alpha^{2}\left\{(1-\alpha) \sigma_{c}-\rho \mu \xi \sigma_{s}\right\}}{3 \beta(1-\gamma) \mu^{2}} \cdot \frac{1}{\lambda^{2}} \\
& +\left[\frac{(3-5 \alpha)(1-\alpha) \sigma_{c}}{6 \mu}+\left(\frac{4}{3} \alpha-1+\mu\right) \rho \xi \sigma_{s}-\frac{1}{\alpha \beta}(1-\mu)(\alpha-1+\mu) \rho \xi \tau_{s}\right] \cdot \frac{1}{\lambda} \\
& +\left[1-\gamma-\frac{(1-\gamma)}{\alpha^{2}}(1-\mu)^{2}\right] \rho \mu \xi \tau_{s}
\end{aligned}
$$

Eqs. (22) and (24) suggest that $v_{u}$ may be expressed as :

$$
v_{u}=f_{1}(\rho, \mu, \xi) \frac{1}{\lambda^{2}}+f_{2}(\rho, \mu, \xi) \frac{1}{\lambda}+f_{3}(\rho, \mu, \xi)
$$

where $f_{i}(i=1,2,3)$ are functions of $\rho, \mu$ and $\xi$. For ordinary beams, the value of $\mu$ may be taken to be equal to unity. If the material properties of the beam are given, then the value of $\xi$ becomes a constant and the value of $v_{u}$ can be written as:

$$
v_{u}=g_{1}(\rho) \frac{1}{\lambda^{2}}+g_{2}(\rho) \frac{1}{\lambda}+g_{3}(\rho)
$$

where $g_{i}(i=1,2,3)$ are functions of $\rho$ and may be assumed to be polynomials of $n$th degree. Consequently, for a given value of $\rho$, the value of $v_{u}$ can be written as a sum of terms containing $1 / \lambda^{2}, 1 / \lambda$ and a constant, that is,

$$
v_{u}=c_{1}^{\prime} / \lambda^{2}+c_{2}^{\prime} / \lambda+c_{3}{ }^{\prime}
$$

where $c_{i}^{\prime}(i=1,2,3)$ are constants, which can be obtained by numerical experiments using Eq. (22) and constraints at (23). Once these values are determined for various values of $\rho$, the values of $v_{u}$ can be written in the form of Eq. (26) by curve-fitting according to the following equations:

$$
\begin{aligned}
& c_{1}^{\prime}=g_{1}(\rho) \\
& c_{2}^{\prime}=g_{2}(\rho) \\
& c_{3}{ }^{\prime}=g_{3}(\rho)
\end{aligned}
$$

The relative beam strength given by

$$
m \equiv M_{u} / M_{f l} \equiv\left(v_{u} b h f_{c}^{\prime}\right)(\lambda d) / M_{f l}
$$

where $M_{u}$ is the ultimate moment corresponding to $v_{u}$ and $M_{f l}$ is the flexural moment capacity of the beam, can be expressed as :

$$
m=c_{1}{ }^{\prime \prime} / \lambda+c_{2}{ }^{\prime \prime}+c_{3}{ }^{\prime \prime} \lambda
$$


in which

$$
c_{i}^{\prime \prime}=\frac{b h d f_{c}^{\prime}}{M_{f l}} c_{i}^{\prime} \quad(i=1,2,3)
$$

It can be seen that with appropriate values of $c_{i}^{\prime}(i=1,2,3)$ and hence $c_{i}^{\prime \prime}(i=1,2,3)$, Eq. (30) is the equation for the curve $1-5-4$ in Fig. 6(b).

\section{COMPARISON WITH AVAILABLE EXPERIMENTAL RESULTS}

In order to show the validity of the analysis, a comparison with available test results by $\mathrm{Kani}^{5)}$ is made. For this purpose, numerical computations of $v_{u}$ were carried out for $\mu=0.8917 \quad(d=271.8 \mathrm{~mm}, h=$ $304.8 \mathrm{~mm}), \xi=13.16\left(f_{c}^{\prime}=26.2 \mathrm{~N} / \mathrm{mm}^{2}, f_{y}=344.7 \mathrm{~N} / \mathrm{mm}^{2}\right)$ with $\rho=0.028,0.0188,0.008$ and $\lambda$ varying from 1 to 8 . The values of $E_{s}$ and $E_{c}$ are taken as $2.0 \times 10^{5} \mathrm{~N} / \mathrm{mm}^{2}$ and $2.4 \times 10^{4} \mathrm{~N} / \mathrm{mm}^{2}$ respectively.

a) Ultimate shear strength and relative beam strength

The results for the ultimate shear strength are tabulated in Table 1. The ratio of test value to calculated value $\left(v_{u \text {,est }} / v_{u \text {,cal }}\right)$ is plotted against the shear span to effective depth ratio $\lambda$ in Fig. 7 . It can be seen that regardless of the types of failure (i. e. flexure or shear) actually observed in tests, the theoretical results agree reasonably well with Kani's results except for very deep beams (i. e. $\lambda=1$ ). For such beams, the effect of bearing plates is significant but this has been neglected in the present study. Using the least square method, the numerical results or Kani's test resuts in Table 1 which correspond to shear failure may be curve-fit by Eq. (27). However, this is outside the scope of the present study as the number of data

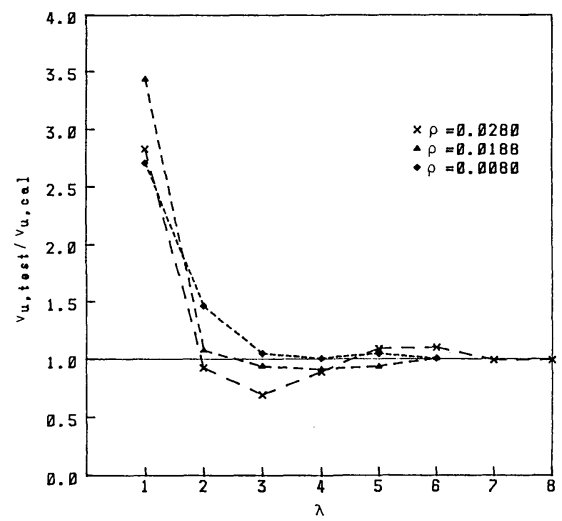

Fig. 7 Values of $v_{u, \text { test }} / v_{u, \text { cal }}$ plotted against Shear Span to Effective Depth Ratio $\lambda$.

Table 1 Comparison of Calculated Ultimate Strength with Test Results for Kani's beams $\left.{ }^{5}\right)\left(f_{c}^{\prime}=26.2 \mathrm{~N} / \mathrm{mm}^{2}, f_{y}=344.7 \mathrm{~N} / \mathrm{mm}^{2}\right)$

\begin{tabular}{|c|c|c|c|c|c|c|c|c|c|}
\hline \multirow[b]{2}{*}{$\lambda$} & \multicolumn{3}{|c|}{$p=0.0280$} & \multicolumn{3}{|c|}{$\rho=0.0188$} & \multicolumn{3}{|c|}{$p=0.0080$} \\
\hline & $v_{u, \text { test }}$ & $\mathrm{v}_{\mathrm{u}, \mathrm{ca} 1}$ & $\begin{array}{l}v_{u, t e s t} \\
v_{u, c a l}\end{array}$ & $v_{u, t e s t}$ & $v_{u, c a 1}$ & \begin{tabular}{|l}
$v_{u, t e s t}$ \\
$v_{u, w a l}$ \\
\end{tabular} & $v_{u, t e s t}$ & $v_{u, c a 1}$ & $\frac{v_{u, t e s t}}{v_{u, c a l}}$ \\
\hline 1 & 0.2239 & 0.0790 & 2.832 & $0.1985^{\circ}$ & 0.0578 & 3.435 & 0.1057 & 0.0390 & 2.707 \\
\hline 2 & 0.1007 & 0.1085 & 0.928 & 0.0824 & 0.0766 & 1.077 & 0.0431 & 0.0294 & 1.466 \\
\hline 3 & 0.0576 & 0.0829 & 0.695 & 0.0458 & 0.0487 & 0.940 & 0.0291 & 0.0276 & 1.053 \\
\hline 4 & 0.0511 & 0.0571 & 0.896 & 0.0423 & 0.0462 & 0.915 & $0.0239^{+}$ & 0.0237 & 1.008 \\
\hline 5 & 0.0468 & 0.0429 & 1.091 & $0.0397^{+}$ & 0.0424 & 0.937 & $0.0199^{+}$ & 0.0190 & 1.048 \\
\hline 6 & 0.0466 & 0.0423 & 1.102 & $0.0355^{+}$ & 0.0353 & 1.007 & $0.0159^{*}$ & 0.0158 & 1.007 \\
\hline 7 & $0.0423^{+}$ & 0.0379 & 0.994 & - & - & - & - & - & - \\
\hline 8 & $0.0366^{+}$ & 0.0375 & 0.982 & - & - & - & - & -- & - \\
\hline
\end{tabular}

* estimated values as actual test data are not available.

+ flexural failure observed in tests. is insufficient for an accurate or reliable dervation of $c_{i}{ }^{\prime} s$ in Eq. (27).

b ) Contribution by compression zone, aggregate interlock and dowel action
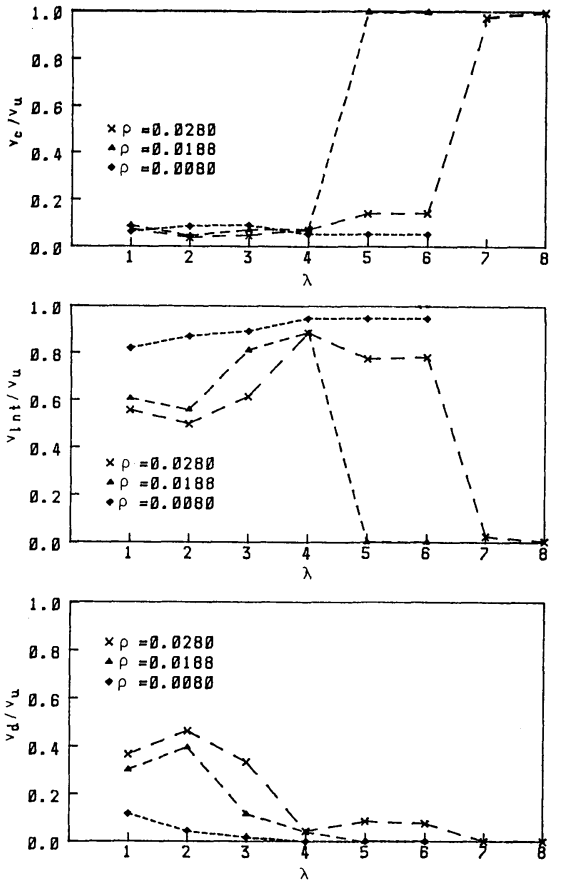

Fig. 8 Contribution to Ultimate Shear Strength by Compression Zone, Aggregate Interlock and Dowel Action. 
It is clear from Eq. (6) or Fig. 2 that the shear force acting on the beam is resisted by the compression zone, aggregate interlock action and dowel action of the tension reinforcement. Once the variables $k$ and $s$ which correspond to $v_{u}$ are determined, the contributions of the various elements to the ultimate strength of the beam can be calculated. The results are shown in Fig. 8.

It can be seen that the contribution of the concrete compression zone $\left(v_{c} / v_{u}\right)$ is rather

low except when flexural failure sets in at $\lambda=7$ for $\rho=0.028$ and at $\lambda=5$ for $\rho=0.0188$. For very low tension reinforcement ratio $\rho=0.008$, the contribution of the compression zone remains low even when flexural failure occurs at $\lambda \geq 4$. This may be due to the solution procedure adopted in this study, as will be explained in the next sub-section. The percentage of the total shear force carried by the compression zone for beam failing by shear does not seem to vary with the values of $\rho$ or $\lambda$. The contribution of the aggregate in terlock action $\left(v_{\mathrm{int}} / v_{u}\right)$ generally increases with shear span to effective depth ratio $\lambda$ for beams failing by shear. It can also be noted that this contribution decreases with an increase in $\rho$. The contribution of the dowel action to the total shear force $\left(v_{d} / v_{u}\right)$ decreases with an increase of $\lambda$, until it becomes zero when flexural failure sets in. This contribution increases with an increase in tension reinforcement ratio $\rho$.

The contribution of the compression zone, aggregate interlock and dowel actions to the ultimate strength is not easily determined from experiments. Hence, there exists a difference in opinion on the relative contribution. Table 2 shows experimental results by several researchers ${ }^{14) ~ 17)}$. These test results were estimated from measurements obtained at the loading stage just prior to collapse of the beams. It can be seen that in general, these results compare favourably with that of the present study, especially in the contribution of the dowel action. The present study, however, predicts a slightly higher contribution by aggregate interlock action and a lower contribution by the concrete compression zone as compared to the test results. This is due to the nature of most experiments, in which either the shear cracks were preformed or the position and shape of the shear cracks were artificially predetermined in the beams.

c ) Collapse modes and state of concrete and steel reinforcement at collapse

The collapse mode is defined in this study by the value of $k$ which gives the ultimate strength $v_{u}$. The predicted collapse modes for the beams investigated are shown in Table 3. Generally, the shear crack assumes the shape of a parabola for
Table 3 Collapse Modes and State of Concrete and Steel Reinforcement at Collapse predicted for Kani's test beams $\left(f_{c}^{\prime}=26.2 \mathrm{~N} / \mathrm{mm}^{2}, f_{y}=344.7 \mathrm{~N} / \mathrm{mm}^{2}\right)$.
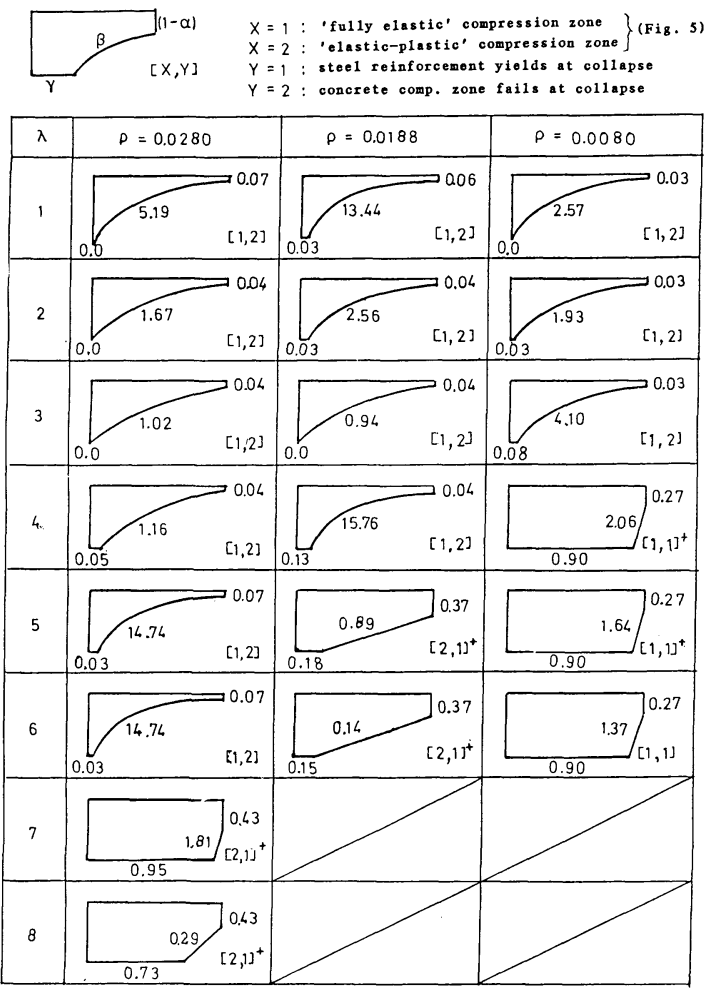

+ flexural failure observed in tests. 
beams which failed by shear in actual tests. The position of the crack may not agree with expeimental observations [Fig. 6]. However, this is of no grave concern as the many shear cracks actually observed in tests have been idealized as one shear crack in the present study [Fig. 2].

For beams which failed by flexure in actual tests, the present study predicts a straight or almost straight crack as the collapse mode. For the beams with $\rho=0.0188$ and $\lambda \geq 5$, the angle of inclination of the crack may look unreasonably low. But, this has no significant meaning beacuse the contribution of the aggregate interlock and dowel actions for these beams is zero [Fig. 8]. For the other beams failing by flexure, the crack is almost vertical, which is therefore in good agreement with experimental observations. It may be noted that for these beams, since the contribution of the dowel action is zero and with the tension reinforcement yielding, a re-distribution of the shear force between the compression zone and aggregate interlock action does not theoretically change the value of the ultimate strength significantly. This explains why the contribution of the aggregate interlock action to the ultimate strength is high even for beams with $\rho$ $=0.008$ which failed by flexure.

It is interesting to note the state of the concrete compression zone and the tension steel reinforcement at collapse. This is indicated by the values of $X$ and $Y$ at the lower right-hand corner of each box in Table 3 . It can be seen that the present study predicts the failure of concrete for beams which failed by shear and the yielding of tension reinforcement for beams failing by flexure. It may thus be concluded that the tension steel reinforcement does not yield for beams failing by shear.

From previous experimental investigations ${ }^{6}$, it is known that the ultimate shear strength of reinforced concrete beams without web reinforcement is dependent on the size, that is the effective depth, of the beam. The formulation in the present study cannot account for such size effect. Nevertheless, since size effect may be related to the maximum aggregate size $^{18)}$ of concrete, it may be incorported into the formulation by introducing appropriate constraints on the interface shear force due to aggregate interlock action. Such constraints may be obtained from experiments on the relation between interlock shear force and maximum aggregate size and length of shear plane.

It is also clear that the present formulation can be easily extended to include beams with compression and web reinforcement and beams subjected to axial forces. The combined upper and lower bound analysis may also be applied to prestressed concrete beams and reinforced concrete slabs by a similar formulation as in the present study.

\section{CONCLUSIONS}

From the above study, the following conclusions may be made :

(1) The ultimate shear strength of reinforced concrete beams without web reinforcement can be evaluated using the combined upper and lower bound analysis outlined in this paper. The contribution of the various elements to the ultimate shear strength can be determined at the same time.

( 2 ) The ultimate shear strength of reinforced concrete beams without web reinforcement can be expressed as a single continuous function of the shear span to depth ratio [Eq. (27)]. By carrying out numerical experiments, formulae for the shear strength of beam may be established.

(3) The contribution of the various elements to the ultimate shear strength depend on the tension reinforcement ratio and shear span to effective depth ratio of the beam [Fig. 8]. For the ranges of tension reinforcement ratio $(0.8 \%$ to $2.8 \%)$ and shear span to effective depth ratio (1 to 6$)$ investigated, the percentages of the ultimate shear strength resisted by the concrete compression zone, aggregate interlock action and dowel action are 5 15\%, 50 90\% and 5 45\% respectively.

(4) The present study indicates that the tension reinforcement does not normally yield in beam which fails in shear.

(5) The present analysis can be easily extended to include the case of reinforced beams with 
compression reinforcement and web reinforcement. It can also be applied to prestressed concrete beams and reinforced concrete slabs.

\section{ACKNOWLEDGEMENT}

This study is supported in part by the Grant-in-Aid for Scientific Research from the Japanese Ministry of Education, Science and Culture. The writers would like to express their thanks to Professor Hajime Okamura of the University of Tokyo for his invaluable discussions during the preparation of the paper.

\section{REFERENCES}

1) ASCE-ACI Committee 426: The Shear Strength of Reinforced Concrete Members, Journal of the Structural Division, ASCE, ST 6, June. 1973.

2) Tan, K. H., Hasegawa, A. and Nishino, F. : A Combined Upper and Lower Bound Analysis and Its Applications, Proceedings of the JSCE, No. 350/ I-2, pp. 125 133, Oct. 1984.

3) Bresler, B. and Pister, K. S. : Strength of Concrete under Combined Stresses, Journal of the ACI, pp. 321 345, Sept. 1958.

4) Park, R. and Paulay, T. : Reinforced Concrete Structures, John Wiley \& Sons, 1975

5) Kani, G. N. J. : Basic Facts Concerning Shear Failure, Journal of the ACI, Proceedings Vol. 63, No. 6, pp. 675 692, June. 1966.

6) Kani, M. W. , Huggins, M. W. and Wittkopp, M. W. : Kani on Shear in Reinforced Concrete, Department of Civil Engineering, University of Toronto, 225 pp., 1979.

7) Okamura, H. and Higai, T. : Proposed Design Equation for Shear Strength of Reinforced Concrete Beams without Web Reinforcement, Proceedings of the JSCE, No.300, pp.131 141. Aug. 1980.

8) Zsutty, T. C. : Beam Shear Strength Prediction by Analysis of Existing Data, Journal of the ACI, Proceedings, V. 65, No. 11, pp. 943 951, Nov. 1968.

9) ACI Committee 318 : Building Code Requirements for Reinforced Concrete (ACI 318-77), American Concrete Institute, Detroit, 102 pp., 1977.

10) Zsutty, T. C. : Shear Strength Prediction for Separate Categories of Simple Beam Tests, Journal of the ACI, Proceedings, V. 68, No. 2 pp. 138 143, Feb. 1971.

11) Kotsovos, M. D. : Mechanisms of 'Shear' Failure, Magazine of Concrete Research, Vol. 35, No. 123, pp. 99 106, June. 1983.

12) Nielsen, M. P. and Braestrup, M. W. : Shear Strength of Prestressed Concrete Beams without Web Reinforcement, Magazine of Concrete Research, Vol. 30, No. 104, pp. 119 128, Sept. 1978.

13) Kemp, K. O. and Al-Safi, M. T. : An Upper-Bound Rigid-Plastic solution for the Shear Failure of Concrete Beams without Shear Reinforcement, Magazine of Concrete Research, Vol. 33, No. 115, pp.96 102, June. 1981.

14) Taylor, H. P. J. : Investigation of the Forces carried across cracks in Reinforced Concrete Beams in Shear by Interlock of Aggregate, Cement and Concrete Association, Technical Report 42.447, 22 pp., Nov. 1970.

15) Fenwick, R. C. and Paulay, T. : Mechanisms of Shear Resistance of Concrete Beams, Journal of the Stuctural Division, Proceedings of the ASCE, Vol.94, No. ST 10, pp.2325 2350, Oct. 1968.

16) Wainstein, D. and Mathey, R. G. : Strains in Beams Having Diagonal Cracks, Journal of the ACI, Proceedings V. 55, No. 6, pp. $717 \sim 728$, Dec. 1958

17) Krefeld, W. J. and Thurston, C. W. : Contribution of Longitudinal Steel to Shear Resistance of Reinforced Concrete Beams, Journal of the ACI, Proceedings V.63, No.3, pp.325 343, Mar. 1966.

18) Bazant, Z. P. and Kim, J. K. : Size Effect in Shear Failure of Longitudinally Reinforced Beams, Journal of the ACI, pp. 456 468, Sep. Oct. 1984

(Received February 13 1985) 